\title{
Pharmacokinetics of combination chemotherapy with paclitaxel and carboplatin in a patient with advanced epithelial ovarian cancer undergoing hemodialysis
}

\author{
JUNICHI KODAMA, AIKO SASAKI, SATOKO MASAHIRO, NORIKO SEKI, TOMOYUKI KUSUMOTO, \\ KEIICHIRO NAKAMURA, ATSUSHI HONGO and YUJI HIRAMATSU \\ Department of Obstetrics and Gynecology, Okayama University Graduate School of Medicine, \\ Dentistry and Pharmaceutical Sciences, Okayama 700-8558, Japan
}

Received November 6, 2009; Accepted March 12, 2010

DOI: $10.3892 /$ ol_00000090

\begin{abstract}
Few reports delineate the pharmacokinetics of combination chemotherapy with paclitaxel and carboplatin in hemodialysis (HD) patients with epithelial ovarian cancer. However, the optimal carboplatin dose and the timing of HD have yet to be elucidated. We presented a case of an advancedstage epithelial ovarian cancer patient with chronic renal failure requiring HD. After 4 courses of combination chemotherapy consisting of paclitaxel and carboplatin, a partial response was obtained; therefore, she underwent interval debulking surgery. Paclitaxel was administered for $3 \mathrm{~h}$ at a dose of 150 $\mathrm{mg} / \mathrm{m}^{2}$, and carboplatin was administered for $1 \mathrm{~h}$ at a dose of 4-7 area under the concentration/time curve (AUC), which was calculated by the Calvert formula. HD was initiated $24 \mathrm{~h}$ after the start of administration of carboplatin and performed for a period of $3 \mathrm{~h}$. Pharmacokinetic studies showed that the AUCs of free platinum and paclitaxel were $3.48-5.55 \mathrm{mg} \cdot \mathrm{min} /$ $\mathrm{ml}$ and $13.5 \mu \mathrm{g} \cdot \mathrm{h} / \mathrm{ml}$, respectively. Combination chemotherapy consisting of paclitaxel and carboplatin is a feasible approach to improving the treatment outcome of epithelial ovarian cancer patients with chronic renal failure requiring HD. The measurement of free platinum is useful in determining the optimal dose of carboplatin in order to obtain an adequate AUC. Determining the dose of carboplatin according to the Calvert formula and initiating HD after $24 \mathrm{~h}$ would ensure a favorable therapeutic effect with limited side effects.
\end{abstract}

Correspondence to: Dr Junichi Kodama, Department of Obstetrics and Gynecology, Okayama University Graduate School of Medicine, Dentistry and Pharmaceutical Sciences, 2-5-1 Shikata-cho, Kita-Ku, Okayama 700-8558, Japan

E-mail: kodama@cc.okayama-u.ac.jp

Key words: epithelial ovarian cancer, carboplatin, paclitaxel, hemodialysis

\section{Introduction}

The management of patients with advanced-stage epithelial ovarian cancer is best achieved through primary cytoreductive surgery and subsequent combination chemotherapy. In the cases of patients with non-optimal debulking, interval cytoreduction is also considered when partial response is obtained. The recommended doses and schedule for combination chemotherapy for advanced-stage epithelial ovarian cancer are: paclitaxel $\left(175 \mathrm{mg} / \mathrm{m}^{2}\right)$ and carboplatin [area under the concentration/time curve (AUC) $5-6 \mathrm{mg} / \mathrm{min} / \mathrm{ml}$ ] every 3 weeks for 6-8 cycles (1).

Many patients undergoing hemodialysis (HD) suffer from various types of cancer. It has been reported that certain types of cancers are more common among HD patients (2). However, few reports exist regarding the pharmacokinetics of combination chemotherapy with paclitaxel and carboplatin in HD patients with epithelial ovarian cancer (3-5).

This study presented a case of a patient with advancedstage epithelial ovarian cancer with chronic renal failure requiring $\mathrm{HD}$. The patient received combination chemotherapy consisting of paclitaxel and carboplatin, and interval debulking surgery. The study analyzed the optimal carboplatin dose administered and timing of HD.

\section{Case report}

The patient was a 52-year-old (gravida 4, para 2) Japanese woman with chronic renal failure who required HD 3 times per week for 14 years. The patient suffered from abdominal distension. At the local clinic, left pleural effusion was indicated by chest radiography, and a cytologic examination revealed adenocarcinoma cells. Magnetic resonance imaging (MRI) of the pelvis revealed tumors in both ovaries and an omental cake with profuse ascites. Computerized tomography did not show any signs of lymph node, lung and liver metastases. The serum levels of CA125 and CA72-4 were 3,008 U/ml (normal, <35 U/ml) and $114 \mathrm{U} / \mathrm{ml}$ (normal, <5.4 U/ $\mathrm{ml})$, respectively; those of other tumor markers, including CEA and CA19-9, were within the normal range. 


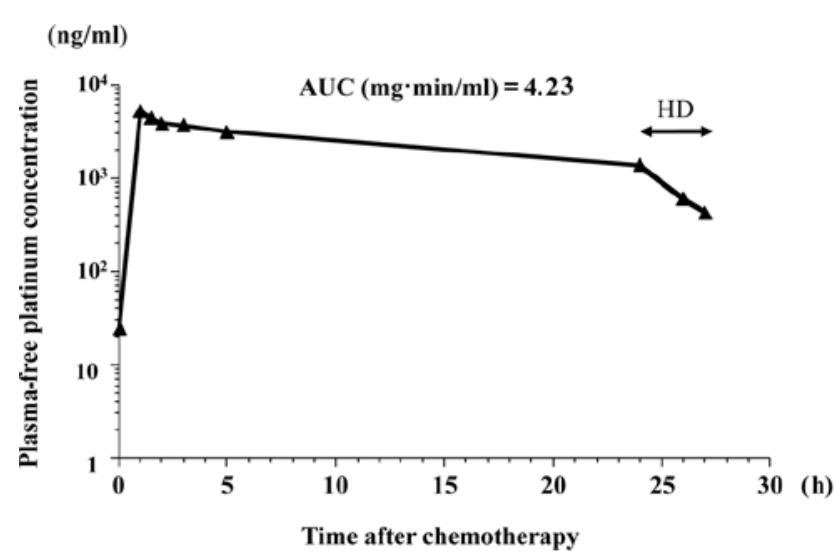

Figure 1. Free platinum concentrations in plasma after the administration of carboplatin in the second course of combination chemotherapy with paclitaxel and carboplatin. Hemodialysis was carried out for $3 \mathrm{~h}$ starting $24 \mathrm{~h}$ after the administration of carboplatin.

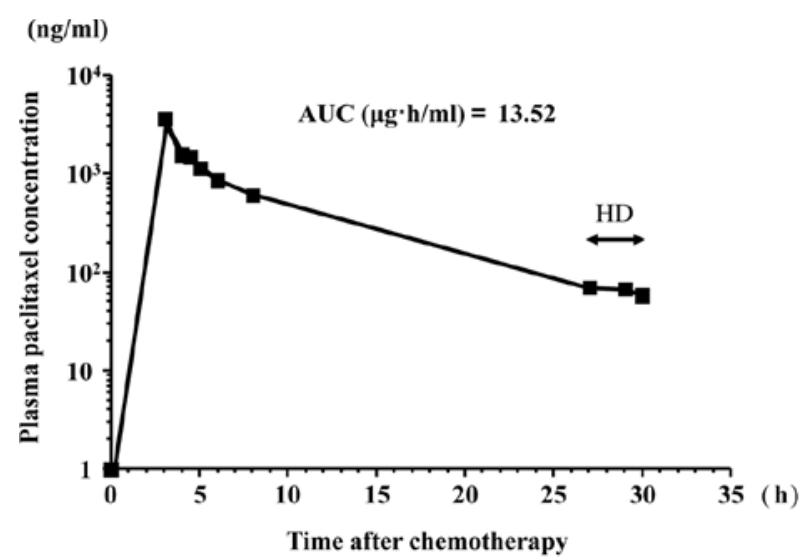

Figure 2. Paclitaxel concentrations in plasma after the administration of paclitaxel in the first course of combination chemotherapy with paclitaxel and carboplatin. Hemodialysis was carried out for $3 \mathrm{~h}$ starting $27 \mathrm{~h}$ after the administration of paclitaxel.

Table I. The maximum plasma concentration and the area under the concentration/time curve.

\begin{tabular}{lcccccc}
\hline Cycle & CBDCA $(\mathrm{mg} / \mathrm{body})$ & $\mathrm{C}_{\max }(\mu \mathrm{g} / \mathrm{ml})$ & $\mathrm{AUC}(\mathrm{mg} \cdot \mathrm{min} / \mathrm{ml})$ & Paclitaxel $\left(\mathrm{mg} / \mathrm{m}^{2}\right)$ & $\mathrm{C}_{\max }(\mu \mathrm{g} / \mathrm{ml})$ & $\mathrm{AUC}(\mu \mathrm{g} \cdot \mathrm{h} / \mathrm{ml})$ \\
\hline 1 & 100 & 3.86 & 3.48 & 150 & 3.60 & 13.5 \\
2 & 150 & 5.12 & 4.23 & 150 & $\mathrm{NA}$ & NA \\
3 & 175 & 7.30 & 5.55 & 150 & $\mathrm{NA}$ & NA \\
4 & 150 & 5.71 & 4.59 & 150 & $\mathrm{NA}$ & NA \\
\hline
\end{tabular}

$\mathrm{C}_{\max }$, plasma maximum concentration; AUC, area under concentration/time curve; NA, not available.

Table II. Nadir blood cell count.

\begin{tabular}{lcccc}
\hline Cycle & WBC nadir $(/ \mu \mathrm{l})$ & Neutrophil nadir $(/ \mu \mathrm{l})$ & Platelets nadir $\left(10^{3} / \mu \mathrm{l}\right)$ & Hemoglobin nadir $(\mathrm{mg} / \mathrm{dl})$ \\
\hline 1 & 3,800 & 2,774 & 24.3 & 6.0 \\
2 & 1,600 & 720 & 14.6 & 6.8 \\
3 & 900 & 297 & 3.3 & 6.1 \\
4 & 2,000 & 1,000 & 6.3 & 6.6 \\
\hline
\end{tabular}

The patient was admitted to our hospital and underwent exploratory laparotomy. A histopathological examination showed a serous papillary adenocarcinoma. The disease was determined to be stage IVA epithelial ovarian cancer according to the International Federation of Gynecology and Obstetrics (FIGO) classification system. The patient was intravenously administered a multidrug regimen consisting of paclitaxel and carboplatin. The optimal dose of paclitaxel was determined to be $150 \mathrm{mg} / \mathrm{m}^{2}$, since it is metabolized mainly in the liver and secreted in bile. The dose of carboplatin was calculated according to Calvert's formula (6): carboplatin dose $(\mathrm{mg} /$ body $)=$ AUC $(\mathrm{mg} / \mathrm{ml} \times \mathrm{min}) \times$ [glomerular filtration rate $(\mathrm{GFR})+25]$. The urinary volume per day of this patient was $0 \mathrm{ml}$; thus, GFR was also determined to be 0 . The patient was initially administered $100 \mathrm{mg} /$ body (AUC $=4 \mathrm{mg} / \mathrm{ml}$ $\mathrm{x}$ min) of carboplatin. Following premedication, paclitaxel was administered for $3 \mathrm{~h}$ and carboplatin for $1 \mathrm{~h}$. HD was initiated $24 \mathrm{~h}$ after administration of carboplatin commenced, and was performed for a period of $3 \mathrm{~h}$.

For the pharmacokinetic analysis of free platinum and paclitaxel, heparinized blood samples $(5 \mathrm{ml})$ were collected at specified times: $0 \mathrm{~h}$ (start of carboplatin infusion); $1 \mathrm{~h}$ (end of carboplatin infusion); 1.5, 2, 4 and 24 h (before HD); 26 and $27 \mathrm{~h}$ (after HD). The samples were centrifuged immediately at 3,000 rpm at $4^{\circ} \mathrm{C}$ for $20 \mathrm{~min}$, and plasma samples were obtained for the measurement of paclitaxel. Aliquots of the plasma were recentrifuged at $3,000 \mathrm{rpm}$ for $10 \mathrm{~min}$ at $4^{\circ} \mathrm{C}$ in a Centrifree Micropartition System (Amicon, Bevery, MA, USA) for the preparation of ultrafilterable platinum. The free platinum and paclitaxel in the plasma were analyzed according to the method of LeRoy et al (7) and a high-performance liquid chromatography UV method (8), respectively. Figs. 1 and 2 show the free platinum concentration in the second course of the chemotherapy and the paclitaxel concentration 
in the first course of the chemotherapy, respectively. Table I summarizes the maximum plasma concentrations $\left(\mathrm{C}_{\max }\right)$ and the AUCs of free platinum and paclitaxel. Table II shows the nadir blood cell counts.

Since mild side effects were observed and the AUC of free platinum was smaller than anticipated in the first course, the dose of carboplatin was increased to $150 \mathrm{mg} /$ body in the second course and to $175 \mathrm{mg} /$ body in the third course. The optimal dose of carboplatin was determined to be $150 \mathrm{mg} /$ body for our patient. The levels of serum CA125 were restored to normal after the patient demonstrated a partial response to 4 courses of TC chemotherapy as determined by MRI. Secondary cytoreductive surgery was performed with macroscopically complete resection, followed by 4 courses of TC therapy.

\section{Discussion}

The present study showed that combination chemotherapy consisting of paclitaxel and carboplatin can be administered to an advanced-stage epithelial ovarian cancer patient with chronic renal failure requiring HD. Paclitaxel is metabolized mainly in the liver and secreted in bile. Only 5-10\% paclitaxel is excreted unchanged by the kidney (9). Therefore, it was reported that the pharmacokinetics of paclitaxel are not altered by HD. The values of $13.5 \mu \mathrm{g} \cdot \mathrm{h} / \mathrm{ml}$ for AUC and $3.6 \mu \mathrm{g} / \mathrm{ml}$ for $\mathrm{C}_{\max }$ when $150 \mathrm{mg} / \mathrm{m}^{2}$ of paclitaxel was administered in the present study for $3 \mathrm{~h}$ are comparable to the values in patients with normal renal function.

The optimal carboplatin dose and timing of HD have yet to be determined. In the present study, the dose of the administered carboplatin was calculated according to the Calvert formula, considering that the GFR was equal to $0 \mathrm{ml} / \mathrm{min}$ and that the extrarenal clearance was $25 \mathrm{ml} / \mathrm{min}$. The extrarenal route of elimination of free platinum corresponds to both the putative hepatic elimination and the plasma and tissue protein binding, which is irreversible for platinum compounds (6). In our case, the mean extrarenal clearance of free platinum was $32 \mathrm{ml} / \mathrm{min}$ (range 29-36). In similar studies involving HD patients, the extrarenal clearance of free platinum was reported to be $20-30 \mathrm{ml} / \mathrm{min}(3,10)$. It is likely that the extrarenal clearance of free platinum differs among patients with chronic renal failure requiring HD. Therefore, the measurement of free platinum may be useful in determining the dose of carboplatin to obtain the correct AUC.

In the present study, HD was initiated $24 \mathrm{~h}$ after the administration of carboplatin. Carboplatin is easily dialyzed in HD patients, since it binds to plasma proteins at a low rate. If no $\mathrm{HD}$ was performed, the AUC of the 4 consecutive courses of chemotherapy would have reached 3.48 vs. 4.10, 4.23 vs. $4.98,5.55$ vs. 6.48 and 4.59 vs. 5.22, respectively. HD starting $24 \mathrm{~h}$ after the infusion of carboplatin for a period of $3 \mathrm{~h}$ resulted in a $15 \%$ reduction in the AUC of free platinum. This value was consistent with that reported by Chatelut et al (3). It was reported that a relatively higher dose of carboplatin (240-300 $\mathrm{mg} / \mathrm{m}^{2}$ ) can be administered in lung cancer patients with renal failure undergoing HD (11-13). In these studies, HD was initiated 30-60 min after the end of carboplatin infusion. The HD setting after the administration of carboplatin is a significant factor, and delay in HD greatly influences the
AUC of free platinum. Therefore, to avoid the risk of hematological toxicity, the dose of carboplatin should be calculated by the Calvert formula, and HD should be initiated after 24 h. Jeyabalan et al demonstrated that carboplatin of a target AUC of 5 (125 mg/body), when combined with paclitaxel (175 $\left.\mathrm{mg} / \mathrm{m}^{2}\right)$, was administered without causing adverse myelosuppression in a patient with ovarian carcinoma undergoing HD (14). These authors did not carry out a pharmacokinetic analysis, and HD was performed $24 \mathrm{~h}$ after the administration of carboplatin.

In conclusion, combination chemotherapy consisting of paclitaxel and carboplatin is a feasible approach to improving the treatment outcome of epithelial ovarian cancer patients with chronic renal failure requiring HD. The measurement of free platinum is useful in determining the ideal dose of carboplatin to obtain an adequate AUC. Even in cases without the measurement of free platinum, determining the dose of carboplatin according to the Calvert formula and initiating $\mathrm{HD}$ after $24 \mathrm{~h}$ would ensure a favorable therapeutic effect with limited side effects.

\section{References}

1. Berek JS and Natarajan S: Ovarian and fallopian cancer. In: Berek \& Novak's Gynecology. 14th edition. Berek JS (ed). Lippincott Williams \& Wilkins, pp1457-1647, 2007.

2. Hollet JL: Screening, diagnosis and treatment of cancer in long-term dialysis patients. Clin J Am Soc Nephrol 2: 604-610, 2007.

3. Chatelut E, Rostaing L, Gualano V, et al: Pharmacokinetics of carboplatin in a patient suffering from advanced ovarian carcinoma with hemodialysis-dependent renal insufficiency. Nephron 66: 157-161, 1994.

4. Watanabe M, Aoki Y, Tomita M, et al: Paclitaxel and carboplatin combination chemotherapy in a hemodialysis patient with advanced ovarian cancer. Gynecol Oncol 84: 335-338, 2002.

5. Yokoyama Y, Futagami M, Higuchi T, et al: Pharmacokinetic analysis of paclitaxel and carboplatin in a patient with advanced ovarian cancer during hemodialysis - case report. Eur J Gynaecol Oncol 27: 437-439, 2006.

6. Calvert AH, Newell DR, Gumbrell LA, et al: Carboplatin dosage: prospective evaluation of a simple formula based on renal function. J Clin Oncol 11: 1748-1756, 1989.

7. LeRoy AF, Wehling ML, Sponseller HL, et al: Analysis of platinum in biological materials by flameless atomic absorption spectrophotometry. Biochem Med 18: 184-191, 1977.

8. Longnecker SM, Donehower RC, Cates AE, et al: Highperformance liquid chromatographic assay for taxol in human plasma and urine and pharmacokinetics in a phase I trial. Cancer Treat Rep 71: 53-59, 1987.

9. Sonnichsen DS and Relling MV: Clinical pharmacokinetics of paclitaxel. Clin Pharmacokinet 27: 256-269, 1994.

10. Motzer RJ, Niedzwiecki D, Isaacs M, et al: Carboplatin-based chemotherapy with pharmacokinetic analysis for patients with hemodialysis-dependent renal insufficiency. Cancer Chemother Pharmacol 27: 234-238, 1990.

11. Yanagawa H, Takishita Y, Bando H, et al: Carboplatin-based chemotherapy in patients undergoing hemodialysis. Anticancer Res 16: 533-536, 1996.

12. Inoue A, Saijo Y, Kikuchi T, et al: Pharmacokinetic analysis of combination chemotherapy with carboplatin and etoposide in small-cell lung cancer patients undergoing hemodialysis. Ann Oncol 15: 51-54, 2004.

13. Takezawa K, Okamoto I, Fukuoka M, et al: Pharmacokinetic analysis of carboplatin and etoposide in a small cell lung cancer patient undergoing hemodialysis. J Thorac Oncol 3: 1073-1075, 2008.

14. Jeyabalan N, Hirte HW and Moens F: Treatment of advanced ovarian carcinoma with carboplatin and paclitaxel in a patient with renal failure. Int J Gynecol Cancer 10: 463-468, 2000. 